\title{
Esparganosis
}

\author{
Patricia Muñoz
}

\section{The sparganosis}

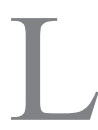

a esparganosis es una parasitosis zoonótica descubierta en China en 1882 por Patrick Manson y posteriormente descrita en humanos en E.U.A en 1908 por Stiles. Es producida por la ingestión de larva plerocercoide denominada espargano. El parásito adulto es una tenia que habita el intestino delgado de perros y gatos, que llega a medir $40 \mathrm{~cm}$. Pertenece a la clase Cestoidea, orden Pseudophyllida, familia Diphyllobotriidae, género Spirometra.

El ciclo de vida de este parásito es muy similar al de Diphyllobotrium latum. Los huevos salen con las heces al medio ambiente, al caer en agua dulce maduran y liberan el coracidio o larva móvil ciliada. Ésta penetra al primer hospedero intermediario, que es usualmente un pequeño crustáceo (del género Cyclops) y ahí se desarrolla la larva procercoide. El segundo hospedero intermediario es generalmente un anfibio o peces que se infectan al ingerir esos organismos con larvas procercoides en su interior. Dentro del segundo hospedero intermediario se desarrolla la larva plerocercoide la cual es el estado evolutivo infectante para el hospedero definitivo. Otros reservorios de la larva plerocercoide son reptiles, aves y mamíferos como osos, cerdos y monos.

Existen varias especies asociadas a este género presentes en el hemisferio oriental tales como Spirometra mansoni, S. erinacei S. ranarum, S.proliferum. Se describen casos en humanos en países como China, Japón, Taiwan, Corea, Vietnam, Tailandia y otros del Sudeste asiático y por otra parte, S. mansonoides que se encuentra en el hemisferio occidental. Esporádicamente ha sido encontrado en Australia, E. U. A, Sudáfrica y América del Sur (Brasil, Ecuador, Paraguay, Colombia, Venezuela, Argentina). El hallazgo de la tenia en hospederos definitivos no es infrecuente en los lugares donde se ha descrito la esparganosis.

Los mecanismos de infección al ser humano incluyen la ingestión de agua contaminada con copépodos (Cyclops) infectados con la larva procercoide; el consumo de carne cruda o poco cocida de cualquiera de los reservorios de la larva plerocercoide (anfibios, reptiles, mamíferos, aves y peces) y por aplicación directa sobre la piel, conjuntivas o vagina de carne cruda de sapos o serpientes usados como cataplasmas para curar enfermedades en algunas tribus originarias.

La larva origina un granuloma que se puede infectar formando un absceso y la sintomatología dependerá del lugar donde se localiza finalmente. Se la ha descrito con mayor frecuencia en tejido subcutáneo como una masa palpable que puede estar fija o migrar, indolora, enrojecida y asociada o no a prurito. Se puede encontrar en otros sitios tales como la pared abdominal, pared torácica, miembros inferiores, escroto, cavidad pleural, pulmones, ojo, órbita, vísceras abdominales y sistema nervioso central. La larva puede alcanzar varios centímetros y vivir hasta 20 años en el hombre. La manifestación más grave es la esparganosis cerebral, la cual se acompaña de cefalea, hemiparesia, hemianopsia, y convulsiones.

El diagnóstico se sospecha por la clínica, los antecedentes epidemiológicos, las imágenes, la serología, el estudio histopatológico y la técnica de RPC, de estar disponible. El tratamiento es la extirpación quirúrgica. Se ha utilizado prazicuantel en dosis altas con resultados poco promisorios.

La prevención se consigue consumiendo carnes bien cocidas de todo tipo y bebiendo sólo agua potable, especialmente los viajeros aventureros que visitan lugares en los que se consumen alimentos más exóticos.

\section{Referencias bibliográficas}

1.- Valerio I, Rodríguez B, Chinchilla M. Primer hallazgo de Spirometra mansoni en Felis domesticus de Costa Rica. Parasitol Latinoam 2004; 59: 162-6

2.- Li M W, Song H Q, Li C, Lin H Y, Xie W T, Lin R Q, et al. Sparganosis in mainland China. Int J Infect Dis 2011; 15: 154-6.

3.- Lezcano A G, Zunt J. Other cestodes sparganosis, coenurosis and Taenia crassiceps cysticercosis. Handbook of Clinical Neurology 2013; 114: 335-45.

4.- CDC. DPDx - Laboratory Identification of Parasitic Diseases of Public Health Concern. Sparganosis. Disponible en: http:// www.cdc.gov/dpdx/sparganosis/index.html (accedido: 21 de mayo de 2015).
Universidad Diego Portales.

Correspondencia a: Patricia Muñoz C. del V. pmunozcdv@gmail.com 